\title{
Cancer Education in Nigeria: Reflections on a Community-based Intervention by a Physicians' Association
}

\author{
Kelechi Eguzo ${ }^{1 *}$, Christie Akwaowo ${ }^{2}$, Uwemedimbuk Ekanem ${ }^{2}$, Catherine Eyo ${ }^{3}$, Emem Abraham $^{4}$ \\ ${ }^{1 *}$ Department of Academic Family Medicine, University of Saskatchewan, Canada \\ ${ }^{2}$ Department of Community Medicine, University of Uyo Teaching Hospital, Uyo, Nigeria \\ ${ }^{3}$ Department of Anesthesiology, University of Uyo Teaching Hospital, Uyo, Nigeria \\ ${ }^{4}$ Department of Ophthalmology, University of Uyo Teaching Hospital, Uyo, Nigeria \\ ${ }^{*}$ Correspondence to: Kelechi Eguzo, Research Coordinator, Department of Academic Family Medicine, University of Saskatchewan, 172 -1621 Albert Street, Regina, \\ SK S4P 2S5, Canada, Tel: 306-766-0395, Fax: 306-766-7135; E-mail: kelechi.eguzo@usask.ca
}

Received: September 01, 2016; Accepted: September 17, 2016; Published: October 06, 2016

\begin{abstract}
Background

Cancer has become an increasingly important source of morbidity and mortality in Nigeria; however our country lacks an organized cancer control system. Low awareness about the disease spectrum among health professionals (HCP) and health policymakers (HPM) is among the challenges affecting cancer control in Nigeria. This reflection describes the process of providing cancer education in Nigeria to HCP and HPM, through the Cancer Control in Primary Care (CCPC) course. It also shares our experiences during the planning, and challenges encountered.
\end{abstract}

\section{Methods}

Medical Women's Association of Nigeria partnered with American Society of Clinical Oncology to deliver cancer education in Akwa Ibom State of Nigeria in February 2016. The main learning objectives were:

- Provide HCP working in Akwa Ibom State with essential knowledge on cancer control

- Provide evidence-based management strategies

- Promote multidisciplinary approach for managing breast and cervical cancers

- Promote the formulation of a cancer control policy in the state

- Share knowledge and experiences with others working in the field

Course lasted 3 days, and featured didactic lectures $(n=11)$; demonstrations and simulations $(n=4)$; and plenary sessions ( $n=7)$. Course was planned using emails, phone calls, WhatsApp ${ }^{\circledR}$ chats and text messages.

\section{Results}

Course was successful with a daily attendance of $>140$ participants comprising physicians, nurses and policymakers in primary, secondary, tertiary and private health facilities in the state. Over $97 \%$ of the participants had improved their knowledge of cancers through the course. We also identified local priorities for cancer control. Use of multiple approaches to recruitment and funding, as well as working with various local partners were crucial to our success.

\section{Conclusion}

Challenges encountered in providing cancer education through this medium include funding, recruitment of participants and event management. Overall, the use of the CСPC course to improve cancer education has proven to be successful, cost-effective and important in building practice networks among HCP and HPM in Akwa Ibom State. We recommend this approach for improving cancer education in resource-limited settings. Outcome of course evaluation will be shared in a different communication.

Keywords: Medical Education, Health Resources, Medical Oncology, Text Messaging, Nigeria, Multimedia, Primary Health Care

\section{Introduction}

Cancer has become an increasingly important source of morbidity and mortality in Nigeria. This trend is largely attributed to improved survival from infectious diseases, increasing life expectancy, as well as rise in risk factors such as cigarette smoking, physical inactivity, obesity and changing dietary patterns. [1-3] Between 2009 and 2010, 4,521 new cases of invasive cancers were reported in some population 
cancer registries, with $66 \%$ of the cancer occurring in females. (1) Common cancers in Nigeria include breast, cervical, prostate and colorectal cancers $[1,2]$. Despite the rising burden of cancer, many countries in sub-Saharan Africa, including Nigeria, do not have organized national cancer control systems $[2,4]$. The absence of an organized cancer control program has adversely affected patient outcomes in Nigeria [5-7]. Cancer control, as used in this discourse refers to an organized public health approach to reduce cancer burden using evidence-based interventions on the cancer continuum, from prevention to palliation.

One of the challenges affecting the control of cancers is the low awareness about the disease spectrum among health professionals (HCP) in the country. Deficient knowledge, ignorance and inappropriate beliefs are among features of poor cancer awareness among HCP in Nigeria [8,9]. It is not surprising then that only about $12 \%$ of physicians in a Nigerian city ever informed their patients about cancer screening. The level of knowledge and clinical competence of health care providers also affect cancer control in Nigeria. Various researchers have highlighted the inadequate training of Nigerian professionals [10,11] For example, there is only one post-basic nursing training program on oncology in Nigeria, in comparison to more than 14 programs in perioperative and psychiatric nursing [12]. The inadequate competence manifests in advocacy/screening practices [13], patient management, [14] and other aspects of cancer care. Some scholars have emphasized the need to improve the knowledge of HCP regarding cancers, as they are a leading source of information for the rest of the public $[13,15,16]$. This informed the decision of Medical Women's Association of Nigeria, Akwa Ibom State Branch (MWANAKS) to lead the cancer-related education of health care professionals in the state.

This reflective article seeks to describe the process of providing cancer education in Nigeria to health care professionals and policy makers, through the Cancer Control in Primary Care course. It also shares our experiences in planning and challenges encountered. The outcome of the conference will be shared in a different communication.

\section{About Medical Women's Association of Nigeria, Akwa Ibom State branch (MWAN - AKS)}

MWAN - AKS is a non-governmental, non-political, non-profit organization of female medical doctors and dentists. Established in 1990 MWAN - AKS has over 30 active members in various medical specialties, including public health, internal medicine, surgery, pathology, anesthesia, ophthalmology, etc. The association meets monthly. MWAN-AKS also provides free screening for cervical and breast cancers to women living in Akwa Ibom State as a way of giving back to the community. Through our professional and community interactions, MWAN-AKS has realized the need for improved training of local health professionals in Akwa Ibom State on cancer control, including advocacy, prevention, diagnosis and treatment, palliation as well as research.

\section{The Cancer Control in Primary Care (CCPC) course}

In February 2016, MWAN-AKS collaborated with American Society of Clinical Oncology (ASCO) to help improve the cancer- related awareness/competence of health care providers and policy makers in Akwa Ibom State, especially at the primary care level. This is motivated by the recognition of training and education as vital components of efforts to tackle the problem of cancer control in Nigeria. ASCO has an existing program called Cancer Control in Primary Care (CCPC) course. The "CCPC course aims to enable participants to better understand resources for cancer diagnosis and treatment in their country and feel more comfortable referring patients suspected of having cancer to a specialist" [17]. MWAN-AKS applied to ASCO in April 2015 for approval to run the CCPC course in Uyo, Nigeria. Akwa Ibom State (with Uyo as capital) has an estimated population of 5,451,277, $49.2 \%$ of whom are women. Majority of the residents come from the Ibibio, Annang and Oro nations. A significant number of residents are farmers and petty traders, although the state has a large public sector [18].

The CCPC course was delivered using a combination of teaching methods. There were didactic lectures with multimedia components $(\mathrm{n}=11)$, demonstrations and simulations $(\mathrm{n}=4)$, as well as plenary sessions $(n=7)$. The lectures included topics in epidemiology, especially regarding breast and cervical cancers. Lectures were simple, easy to understand and key concepts were explained exhaustively. Short videos, hands-on demonstrations with models and color images were used to improve retention and hold the attention of the participants. Interactive sessions were used to discuss issues such as cancer control framework, inter-professional collaboration and strategies for implementing the lessons from the conference. Furthermore, there were real-life; expository accounts from a cancer survivor, relatives of cancer patients and health professionals who had worked with cancer patients, on their experiences with cancer care in the State and Country. This helped demystify the disease spectrum and set the stage for open discussions.

The course was held over 3 days (February 17-19), with each day lasting 8 hours. Each day of the conference began with a summary and questions from the previous day. Course participants were health care professionals (physicians and nurses), primary health care coordinators in each of the 31 Local Government Areas in Akwa Ibom State as well as students (medical and nursing). The faculty for the course included surgeon (1), family physician (1), Community Physicians (3), Anesthesiologist (1), Obstetrician/Gynecologist (1) and Nurse (1). Funding for the course was largely provided by the American Society of Clinical Oncology (ASCO). Other organizations that supported the conference include Clement Isong Foundation, Obong University, Zitadel Medical Diagnostics, Akwa Ibom State Ministry of Health, University of Uyo Teaching Hospital and StandUp to Cancer Foundation.

\section{Conference planning}

\section{Communication}

The planning of this conference involved individuals in 3 countries (Nigeria, United States and Canada), most of whom were on different time zones. As can be imagined, one challenge was finding a suitable time to hold meetings. We relied heavily on emails, telephone calls, text messaging and social media chats (WhatsApp ${ }^{\circ}$ ). Bulky information (such as programs and budgets) was shared through 
emails. This helped reduce ambiguity. We held more than 3 conference phone calls during the planning of the conference. We also created a WhatsApp group to facilitate discussions. Urgent information was shared through text messages. We considered this to be the quickest way to reach people as most people have their phones handy. To attract policy makers, personal letters were sent to them and these were followed up with phone calls and reminders via text messaging as the date of the event drew closer.

The following is an estimated use of the respective communication media: E-mails $>200$; text messages $>230$; WhatsApp chats $>356$.

In reflecting on the communication between team members during the planning of the conference, we can say that using multiple media was quite helpful. Given the fact that internet service was not very reliable in Nigeria, members were able to get prompt updates through text messages. It also helped us to be more inclusive in our planning. We are actually thrilled at the capability of social media (WhatsApp ${ }^{\circledR}$ ) to aid in the planning of this event. Unfortunately, not all members of our planning committee were able to use WhatsApp ${ }^{\circledast}$

The planning of this event had dual leadership; one aspect focused on course content and delivery (led by Dr. Eguzo) while the other component focused on course administration (led by Dr. Akwaowo). A local organizing committee was constituted to help with event planning/management, fund raising, recruitment of participants and other logistics. We created sub-committees to look after Registration, Venue, Publicity, Entertainment and Communiqué. The leadership of MWAN-AKS was quite involved, attracting top government functionaries and other medical leaders to the conference. We also involved the national leadership of MWAN in the planning of this conference, as it would reflect on the larger organization.

The main learning objectives for conference delegates were the following:

- To provide health care providers (physicians and nurses) working in primary care in Akwa Ibom State with essential knowledge on cancer control

- To provide evidence-based management strategies

- To promote multidisciplinary approach to help improve care for people dealing with cancers, especially for breast and cervical cancers

- To promote the formulation of a cancer control policy in the State

- Share knowledge and common experiences with others working in the field

We also sought to do a pilot research on the cancer-related experience and expectations of patients, health care professionals and health policymakers in Akwa Ibom State regarding cancer control. In addition, pre-and post-conference questionnaires were designed to gain an understanding of the concerns and priorities of participants. They also assessed how the workshop may influence their professional practice in the future, as well as their evaluation of the speakers/ conference organization.

\section{Recruitment}

We used a multi-pronged approach to recruit conference participants. Our target was to recruit at least 120 individuals from across the state. First, we worked with the Ministry of Local Government and Chieftaincy Affairs (MOLGCA) to recruit people from the Primary Health Care system. The leadership of MOLGCA contacted the primary health care coordinators in each LGA to send at least 2 individuals (a nurse and the PHC coordinator) to attend. Through the Hospital Management Board, we recruited physicians and nurses who work in the secondary health care sector (general hospitals). We worked with the local branch of Nigerian Medical Association to recruit physicians in private practice. The University of Uyo Teaching Hospital was asked to send resident doctors and nurses to attend the conference. We also recruited students from University of Uyo and Methodist General Hospital School of Nursing, Ituk Mbang.

Individuals who were selected for the course were informed through a combination of methods. Formal circulars/letters were sent from the relevant government agencies. Non-governmental organizations, like the Nigerian Medical Association, used text messaging (SMS) to inform their members. Due to space considerations, we did not open the invitation to everyone who could attend. We had also considered advertising the course using Facebook groups. The conference was well-attended by over 140 individuals daily (17\% above target). The majority of participants (51\%) were nurses from Akwa Ibom State, especially those working in Primary Health Care facilities across the 31 Local Government Areas in the state.

\section{Challenges}

Organizing a workshop of this nature commonly poses some challenges. Getting all planners on the same page was not an easy task, considering the differences in time, location and professional perspectives. The guidelines and conference agenda template provided by ASCO were helpful in focusing our planning. We also kept open minds in welcoming new ideas. One expression that was used frequently during our planning discussions was that 'nothing is set in stone. This helped us navigate through many of the interpersonal issues that typically affect event planning.

Funding was another challenge with organizing the conference. Although ASCO had approved a grant for the conference, we had difficulty with accessing funds. This was due to changes in Nigerian banking regulations and other bureaucratic delays. In retrospect, we have learned that it is better to sort out the banking aspect of things at least 4 weeks before the conference starts. In addition, we had difficulties with raising funds locally, as Nigeria was experiencing economic difficulties at the time. Our expectations were to access funds from the government and the oil industry. However, Nigeria was facing economic crises around the time of the conference, thus making it difficult to access funds from that source. It would have been better to explore other potential funders early, especially the banking industry.

Despite contacting the Hospitals Management Board about two months prior to the workshop, most of the physicians expected did not get the letters of invitation. This led to the skewed participation on Day 1 as doctors invited from the Local Government Areas (equivalent to districts) failed to turn up and there were more nurses present. We managed this challenge by marketing the event as a Continuing Medical Education activity (awarding CME points) to 
all doctors in the state. New invitations were sent via text messages through the Nigerian Medical Association and Association of General and Private Medical Practitioners of Nigeria (AGPMPN) in the State. The Local Organizing Committee also invited members of the private sector within the state capital to the workshop. This led to an increase the number of participants registration. By the second and third days, eighty doctors who were not on the original invitation list participated in the workshop.

We thank the Local Government Service Commission for the donation of their auditorium although we experienced some challenges in using the venue with regards to logistics. Choosing a venue is very important in holding a successful conference [19]. Interestingly, few of the conference participants complained about the challenges with the venue; in fact $97 \%$ of them rated the conference to be very successful and impactful. This suggests that enriching a conference with quality content could compensate for deficiencies encountered at the venue. Findings from this conference will be shared in another communication.

\section{Conclusion}

Cancer control is an emerging public health concept in Nigeria, given the rising cancer morbidity and mortality. In the midst of significant challenges to cancer control in Nigerian and other resource-limited countries, cancer control workshops, like the CCPC, provide a good starting point to improve cancer care. We used multiple approaches to improve our planning, and explored an array of options to fund the conference. Our approach was very cost-effective and led to the building of important networks among clinicians and policy makers across Akwa Ibom State. We were also able to identify local priorities for cancer control.

Following the successful conclusion of the CCPC conference, MWAN-AKS was commissioned by the Akwa Ibom State Ministry of Health to provide breast and cervical cancer screening services to women in Uyo as part of the 2016 International Women's Day. Our organization is also making plans to further share the content of this conference with more health providers in the grassroots by organizing step-down workshops in each of the 3 senatorial district in Akwa Ibom State. It is our expectation that we will as well be approved by ASCO to hold the Multidisciplinary Cancer Management Course in 2017. This course will build on the gains made from the CCPC course, and further strengthen our efforts at building a local cancer control system. Finally, in the words of Farmer et al (20), "the time has come to challenge and disprove the widespread assumption that cancer will remain untreated in poor countries".

\section{References}

1. Jedy-Agba E, Curado MP, Ogunbiyi O, Oga E, Fabowale T, Igbinoba F, et al. (2013) Cancer incidence in Nigeria: a report from population-based cancer registries. Cancer Epidemiology 36:e271-8.

2. Eguzo K, Camazine B (2013) Beyond limitations: practical strategies for improving cancer care in Nigeria. Asian Pacific Journal of Cancer Prevention: Apjcp 14:3363-8.

3. Love RR, Ginsburg OM, Coleman CN (2012) Public health oncology: a framework for progress in low- and middle-income countries. Ann Oncol 23: 3040-3045. [crossref]

4. Adebamowo C (2010) Bringing vision and leadership to confront the cancer epidemic in Africa... Clement A. Adebamowo. ASCO Connection 1:32-33.
5. Okobia MN, Aligbe JU (2005) Pattern of malignant diseases at the University of Benin Teaching Hospital. Trop Doct 35: 91-92. [crossref]

6. Abubakar Malami S, Pindiga UH, Abimiku BA, Mungadi IA, Abdullahi AD, Dauda A, et al. (2007) A descriptive retrospective study of the pattern of malignant diseases in Sokoto, North Western Nigeria. Journal of Medical Sciences 7:1033-38.

7. Mohammed AZ, Edino ST, Ochicha O, Gwarzo AK, Samaila AA (2008) Cancer in Nigeria: a 10-year analysis of the Kano cancer registry. Nigerian Journal of Medicine: Journal of the National Association of Resident Doctors of Nigeria 17:280-4.

8. Gharoro EP, Ikeanyi EN (2006) An appraisal of the level of awareness and utilization of the Pap smear as a cervical cancer screening test among female health workers in a tertiary health institution. International Journal of Gynecological Cancer 16:1063-8.

9. Unang I, Abasiattai AM, Udoma E (2011) Awareness and practice of cervical smear as a screening procedure for cervical cancer among female nurses in a tertiary hospital in south-south Nigeria. Turk Silahl Kuvvetleri, Koruyucu Hekimlik Bulteni 10:675-80.

10. Nwogu C, Mahoney M, George S, Dy G, Hartman H, Animashaun M, et al (2014) Promoting cancer control training in resource limited environments: Lagos, Nigeria. Journal of Cancer Education 29:14-8.

11. Ogboli-Nwasor E, Makama J, Yusufu L (2013) Evaluation of knowledge of cancer pain management among medical practitioners in a low-resource setting. $J$ Pain Res 6: 71-77. [crossref]

12. Obong G (2016) List of Approved Schools. Abjua, Nigeria: Nursing and Midwifery Council of Nigeria.

13. Anorlu RI, Ribiu KA, Abudu OO, Ola ER (2007) Cervical cancer screening practices among general practitioners in Lagos Nigeria. Journal of Obstetrics \& Gynaecology 27:181-4.

14. Nwankwo KC, Anarado AN, Ezeome ER (2013) Attitudes of cancer patients in a university teaching hospital in southeast Nigeria on disclosure of cancer information. Psycho-Oncology 22:1829-33.

15. Anyebe EE, Opaluwa SA, Muktar HM, Philip F (2014) Knowledge and practice of cervical cancer screening amongst nurses in Ahmadu Bello University Teaching Hospital Zaria. Research on Humanities and Social Sciences 4:33-40.

16. Nwogu C, Mahoney M, George S, Dy G, Hartman H, Animashaun M, et al. (2014) Promoting cancer control training in resource limited environments: Lagos, Nigeria. Journal of cancer education : the official journal of the American Association for Cancer Education 29:14-18.

17. Affairs AI (2016) ASCO's first Cancer Control in Primary Care Course in India a Success. ASCO Connection.

18. Communication AISMoIa (2016) AKWA IBOM STATE HISTORY. Akwa Ibom State Government. The Ten Commandments for Organizing a Conference. Journal of Economic Surveys 11:231-33.

19. McAleer M. The Ten Commandments for Organizing a Conference. Journal of Economic Surveys 1997;11(2):231-33.

20. Farmer P, Frenk J, Knaul FM, Shulman LN, Alleyne G, et al. (2010) Expansion of cancer care and control in countries of low and middle income: a call to action. Lancet 376: 1186-1193. [crossref]

\section{Citation:}

Kelechi Eguzo, Christie Akwaowo, UwemedimbukEkanem, Catherine Eyo, Emem Abraham(2016) Cancer Education in Nigeria: Reflections On a Community-Based Intervention by A Physicians' Association. Can Stu The J Volume 1(1): 1-4 